\title{
Interventricular septal rupture caused by vehicular trauma
}

\author{
Sébastien Robinet, $\mathrm{MD}^{a, *}$, Philippe Morimont, $\mathrm{MD}^{b}$, \\ Bernard Lambermont, $\mathrm{MD}, \mathrm{PhD}^{b}$, Jean Olivier Defraigne, $\mathrm{MD}, \mathrm{PhD}^{\mathrm{c}}$ \\ ${ }^{a}$ Department of Cardiology, University Hospital of Liège, Belgium \\ ${ }^{\mathrm{b}}$ Medical Intensive Care Unit, University Hospital of Liège, Belgium \\ ${ }^{\mathrm{c}}$ Department of Cardiovascular Surgery, University Hospital of Liège, Belgium
}

\section{A R T I C L E I N F O}

Article history:

Received 22 February 2011

Revised 9 April 2011

Accepted 13 April 2011

Online

\begin{abstract}
A B S T R A C T
We report the case of a patient admitted at the emergency unit after a severe car accident. As ECG showed a ST segment elevation in all leads, the working diagnosis was coronary dissection. Coronary angiography revealed a large interventricular septal rupture, confirmed by echocardiography. After discussion and as haemodynamics permitted, 6 weeks of medical observation were decided. A surgical repair was then performed, and provided a perfect repair of the shunt. We discuss about the prevalence and management of this rare traumatic complication.
\end{abstract}

\section{CASE RePORT}

We report the case of a 25 -year-old man involved in a car accident with rapid deceleration. On admission to the emergency unit, vital signs were a heart rate of $100 \mathrm{~min}^{-1}$, blood pressure of 120/58 $\mathrm{mm} \mathrm{Hg}$, and oxygen saturation via pulse oximetry of $100 \%$ on high flow oxygen. Concussive symptoms were noted. The clinical examination revealed a loud systolic murmur and bibasal decreased breath sounds. The patient had no history of cardiovascular problems, as confirmed by a clinical evaluation for military service several years before admission.

The 12-lead electrocardiogram showed a complete right bundle branch block and ST-segment elevation in all leads. Laboratory analysis showed elevated creatine kinase-MB and troponin I. The patient was then transferred to the University Hospital of Liège for coronary angiography. The working diagnosis was coronary dissection.

Angiography showed no arterial abnormalities, but revealed an apical and posterior transeptal interventricular left-right shunt. Transthoracic echocardiography confirmed septal rupture with a pulmonary/ systemic output ratio of 1.7. Neither right ventricular dilatation nor pericardial effusion was noted. The septal defect diameter was $8 \mathrm{~mm}$.

The patient's hemodynamics were stable, and he showed no clinical signs of right-sided heart failure. In this situation, we decided not to perform any emergency cardiac surgery, because the injured heart tissue could lead to a suture weakness or rupture.

Transthoracic echocardiography follow-up was performed twice daily and identified an intermittent, noncompressive pericardial effusion, with spontaneous

\footnotetext{
* Corresponding author: Sébastien Robinet, MD, Centre Hospitalier Universitaire de Liege, Department of Cardiology, Rue des Mineurs, NÂ 23, 4000 Liege, Belgium.

E-mail address: robinetseb@yahoo.fr (S. Robinet). 
resolution. A minor enlargement of the shunt was also noted during the first 2 weeks of its echocardiographic follow-up, without deterioration of the clinical state of the patient. Rapid improvement of ST- and T-wave changes were seen over the next 3 days.

The opinion of the cardiologist and surgeons caring for the patient was to wait several weeks to allow a regression of the cardiac contusion and septal fibrosis, to ensure safer suture conditions. Functional reevaluation was planned after 6 to 8 weeks of medical observation.

The patient was discharged after 3 weeks, with a stable $14-\mathrm{mm}$ interventricular shunt and no right ventricular dilatation or clinical sign of high-output heart failure (Figure 1).

Six weeks later, surgical correction of the interventricular septal rupture was performed. Under cardiopulmonary bypass, the right ventricle was opened near the apex. Repair of the septal rupture was performed with a sandwich technique, using auto- and allografts of the pericardium (Figure 2). Transthoracic echocardiography revealed a complete repair, and no leakage was noted around the pericardial patches. Follow-up was uncomplicated, and the patient was rapidly discharged from the hospital.

At the postoperative cardiology consultation 6 weeks later, the patient showed no signs or symptoms of cardiac dysfunction, except sporadic positional chest pain. He progressively resumed a full active life. The follow-up echocardiographic examination confirmed complete correction of the shunt. A limited apical posterior septal infarction was identified, associated with normal left ventricular ejection fraction and no right ventricular dilatation.

\section{Discussion}

Interventricular septal rupture is a rare complication of blunt chest trauma. Most septal defects are due to myocardial infarction or penetrating chest trauma. Large autopsy series report a low rate $(0.002 \%)$ of isolated traumatic ventricular septal rupture due to car accidents. ${ }^{1}$

Clinical symptoms range from asymptomatic to cardiogenic shock or death and can appear immediately or days to weeks after the initial accident. Chest radiography and electrocardiographic evaluation are nonspecific, usually showing increased pulmonary blood flow and repolarization abnormalities due to myocardial contusion. ${ }^{1}$ Coronary artery dissection also can be suspected, especially in case of rapid deceleration trauma, and lead to a coronary angiography that then reveals the shunt.

In the presence of a new pansystolic cardiac murmur with no history of cardiovascular disease, echocardiography would seem to be the most useful examination to proceed with initially. This examination can also exclude other causes of the cardiac murmur, such as undiagnosed or induced valve failure or injuries.

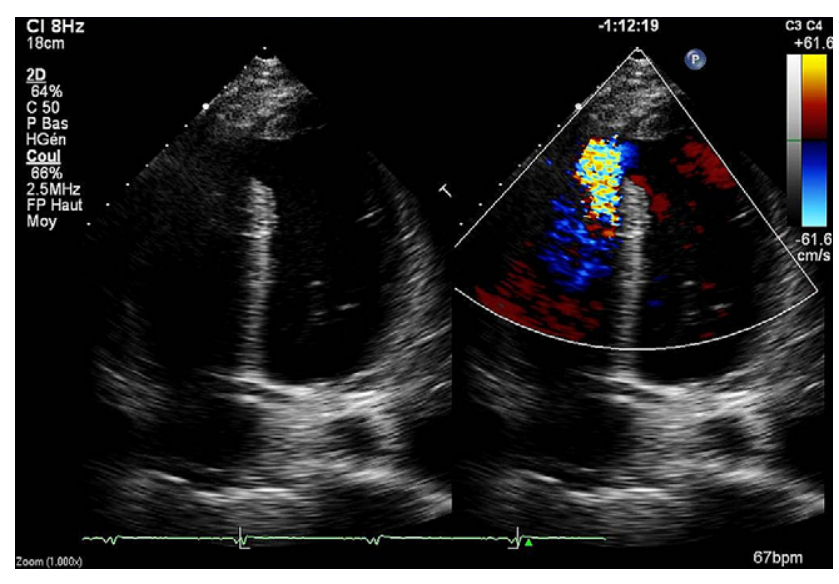

Figure 1 - Echocardiographic view of the interventricular septal rupture.

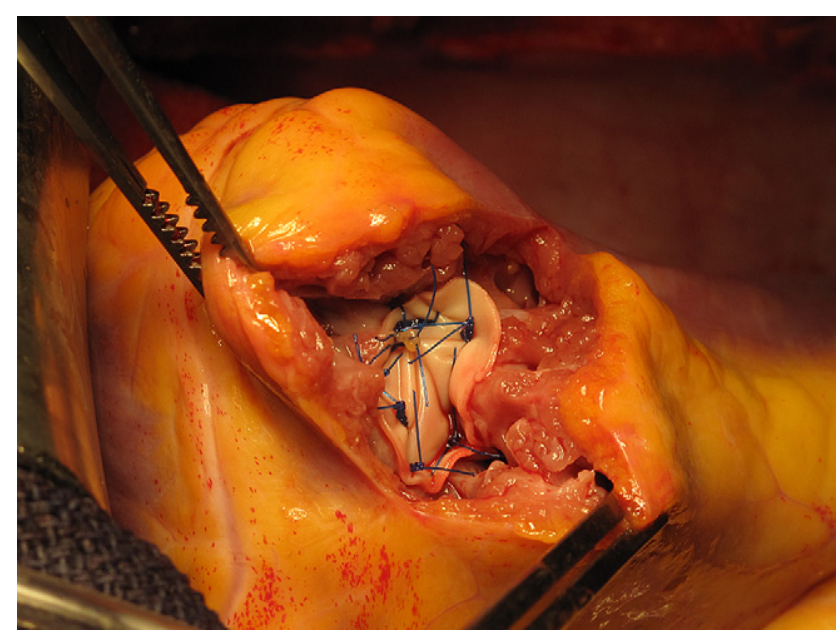

Figure 2 - Repaired interventricular septal defect, using auto- and allopericardial grafts.

On the basis of the Qp/Qs ratio, 3 different therapeutic options may be proposed:

First, small interventricular defects with a low Qp/ Qs ratio $(<2)$ can be managed conservatively, based on the hemodynamic status. Stable clinical conditions are commonly observed for years in these cases, and spontaneous closure of traumatic ventricular defects has been reported. ${ }^{2-4}$

Second, in large interventricular shunts (Qp/Qs > 2) with stable hemodynamics, medical management is proposed first, while waiting for regression of the contusion and cardiac scarring. This interval may provide safer surgical conditions and improve the risk/ benefit ratio. In this specific case, the patient was stable, but as the progressive extent of the shunt grew from 8 to $14 \mathrm{~mm}$ with a proportional Qp/Qs ratio, we considered that surgical repair should be performed after a period of medical observation.

Finally, large interventricular shunts and unstable hemodynamics require immediate surgical management. Percutaneous transcatheter closure has recently 
been described as a viable alternative, especially in the case of relative contraindications for repeated surgical repair. ${ }^{2,4,5}$ In this specific case, the diameter of the shunt, its apical and inferior position, and the lack of septal seating around the injury were not favorable for this option.

\section{REFERENCES}

1. de Mello RP, Santana MV, Silva MA, Esteves C, Pedra C, Thome A, et al. Ventricular septal rupture following blunt chest trauma. Arq Bras Cardiol 2006;87:168-71.
2. Lee R, Gill DS, Yong QW. Isolated rupture of the interventricular septum due to fall from a height. Int $J$ Cardiol 2005;98:525-6.

3. Ilia R, Goldfarb B, Wanderman KL, Gueron $\mathrm{M}$. Spontaneous closure of a traumatic ventricular septal defect after blunt trauma documented by serial echocardiography. J Am Soc Echocardiogr 1992;5:203-5.

4. Iro H, Saito S, Miyahara K, Takemura H, Sawaki S, Matsuura A. Traumatic ventricular septal defect following a stab wound of the chest. Gen Thorac Cardiovasc Surg 2009;57:148-50.

5. Martinez MW, Mookadam F, Sun Y, Hagler DJ.

Transcatheter closure of ischemic and post-traumatic ventricular septal ruptures. Catheter Cardiovasc Interv 2007;69:403-7. 